\title{
The Utility of Nucleolar Organizer Regions Quantitation in Early Prediction of Lung Neoplastic Transformation
}

Hussain G. Ahmed ${ }^{1}$, Amel B. El Hag ${ }^{2}$, Naif K. Binsaleh ${ }^{3}$, Gamal Eldin Mohamed O. Elhussein ${ }^{4}$, Malik Asif Hussain ${ }^{2}$, Mohamed Ahmed Babikir I. Bealy ${ }^{2}$, Emad Abboh A. Abboh ${ }^{2}$, Hisham Sherfi ${ }^{5}$

1. Pathology, College of Medicine, University of Ha'il, Ha'il, SAU 2. Pathology, College of Medicine, University of Ha'il, Ha'il, SAU 3. Clinical Laboratory, College of Applied Medical Science, University of Ha'il, Ha'il, SAU 4. Pediatrics, College of Medicine, University of Ha'il, Ha'il, SAU 5. Medicine, College of Medicine, University of Ha'il, Ha'il, SAU

Corresponding author: Hussain G. Ahmed, hussaingad5@gmail.com

\section{Abstract}

Background: Cancer burden can be reduced by early detection of early neoplastic changes applying suitable screening methods. This study aimed to assess the utility of nucleolar organizer regions (NORs) quantitation in early prediction of lung neoplastic transformation.

Methodology: This study investigated 200 apparently healthy individuals categorized into two groups; smoking exposed individuals ( $\mathrm{N}=100)$, and were categorized as cases, and smoking nonexposed $(\mathrm{N}=100)$, and were ascertained as controls. Sputum specimen was attained from each participant (paying all indispensable safety precautions and sample adequacy processes).

Results: Out of the 200 volunteers assessed in the present study, mean NORs counts of $>2.00$ were identified in 16/200(8\%) of the study subjects. All 16/16(100\%) cases were found with lung epithelial metaplasia (squamous metaplasia). Out of the 100 cases, mean NORs counts of $>2.00$ were identified in 16/100(16\%), hence, all the controls were identified with mean NORs counts of $<2.00$. The risk of lung cellular proliferative changes associated with smoking exposure are odds ratio $(\mathrm{OR})(95 \%$ confidence interval, $\mathrm{CI})=$ $39.2485(2.3199-664.0052), \mathrm{p}=0.0110$, $\mathrm{z}$ statistic $=2.543$.

Conclusion: NORs count is a simple, specific, cost-effective, and reliable method that can give a quantitative measurement for the risk of lung neoplastic transformation. For at risk-population (tobacco users), it is recommended to perform the argyrophilic NORs (AgNORs) method beside sputum cytology.

Review began 11/04/2020 Review ended 11/08/2020 Published 11/28/2020

(c) Copyright 2020 Ahmed et al. This is an open access article distributed under the terms of the Creative Commons Attribution License CC-BY 4.0., which permits unrestricted use, distribution, and reproduction in any medium, provided the original author and source are credited.
Categories: Pathology

Keywords: agnors, nor, lung cancer, cigarette smoking, saudi arabia

\section{Introduction}

Over $85 \%$ of lung cancer cases have been linked to smoking [1]. Smoking causes about 1.7 million causalities per annum globally [2]. Early detection of carcinoma is important from a therapeutic point. Late-stage diagnosis of lung cancers is associated with very high mortality compared to early diagnosis [3]. Lung cancers have the least survival rate for five years amongst all malignancies [4]. Lung cancer screening has been reported to reduce mortality [5]. The screening and smoking cessation have even more reduction in the death rate [6]. A bonus benefit of screening is the opportunity to encourage and engage smokers in quitting programs [7]. The people at higher risk of having lung malignancy based on their age and history of smoking are recommended to get screening for lung cancers [8].

Nucleolar organizer regions (NORs) are loops of DNA that have encoding for rRNA and play an important role in protein synthesis in cells. They chemically bind with silver, the complex formed is referred to as argyrophilic NOR (AgNOR) which is observed to count their numbers [9].

DNA damage related changes in NORs are important [10]. The NORs numbers can be used as an important marker in tumor studies [11]. Malignant lesions possess NORs in higher numbers and this increased number is also linked with poor prognosis. Their number reflects the cellular division activity as well as dysplasia in many tissues [12]. Their number can even be used to study the effects of pollutants or therapy on cell kinetics [13]. A higher number of NORs can be used to decide treatment options such as whether the systemic therapy for lung cancer patients is required or not. There is a difference in NORs at various stages and in different types of lung cancers. For example, NORs can be used to monitor the prognosis and recurrence of nonsmall cell lung cancers [14].

Recent research is focusing on revealing further genomic details about human NORs. It is important to investigate the relationship between various diseases as well as the aging process and NORs [10]. As the 
AgNOR mean count is a noninvasive, cost-effective procedure, the raised question is whether it is the most suitable simple method for screening at risk population, such as smokers. Current diagnostics and treatment procedures need further research. Therefore, the current study aimed to assess the utility of NORs quantitation in early prediction of lung neoplastic transformation.

\section{Materials And Methods}

In this case-control study, 200 apparently healthy volunteers were randomly selected by simple random method regardless of their demographical characteristics. Study subjects were categorized into two groups; smoking exposed individuals $(\mathrm{N}=100)$, and were categorized as cases, and smoking nonexposed $(\mathrm{N}=100)$, and were ascertained as controls. Sputum specimen was attained from each participant (paying all indispensable safety precautions and sample adequacy processes). Cellular constituents were cautiously selected from the colored sputum matters and then were evenly smeared on a cleaned frosted-end glass-slide. Each smear was immediately fixed in $95 \%$ ethyl alcohol for 15 minutes. The smears were then transported to the histopathology laboratory at the College of Medicine, University of Ha'il, Saudi Arabia for staining and diagnosis. All smears were stained using the AgNORs staining method adopting the procedure described by Ahmed and Babiker [15].

\section{Ethical consent}

Each participant was asked to sign a written ethical consent before the taking of the biological specimen. The protocol for the study was also approved by the Ethical Committee at the College of Medicine, University of Ha'il. Ethical Approval Number: HREC 00121/CM-UOH.04/20.

\section{Data analysis}

All obtained data were entered via a computer software SPSS and analyzed to obtain the Chi-square test (pvalue $<0.05$ considered statistically significant), odds ratio (OR), applying a 95\% confidence interval (CI).

\section{Results}

The age and sex distribution were relatively similar in the present study, as indicated in Table 1 and Figure 1. Out of the 200 volunteers assessed in the present study, mean NORs counts of $>2.00$ were identified in $16 / 200(8 \%)$ of the study subjects as shown in Figures $2-3$, and the remaining $184 / 200(92 \%)$ were found with mean NORs counts of $<2.00$. All 16/16(100\%) cases were found with lung epithelial metaplasia (squamous metaplasia). Out of the 100 cases, mean NORs counts of $>2.00$ were identified in $16 / 100(16 \%$ ), hence, all the controls were identified with mean NORs counts of $<2.00$. The risk of lung cellular proliferative changes associated with smoking exposure and the OR and 95\% CI was; OR $(95 \% \mathrm{CI})=39.2485(2.3199-664.0052), \mathrm{p}=$ 0.0110 , z statistic $=2.543$, as indicated in Table 1, Figures 1, 4 . The 16 individuals with mean NORs counts of $>2.00$ were males. Higher mean NORs counts relatively increased with the increase of age, and duration of exposure to tobacco smoking, as shown in Figures 5-6. 


\section{Cureus}

\begin{tabular}{|c|c|c|c|}
\hline Variable & Cases & Controls & Total \\
\hline \multicolumn{4}{|l|}{ Sex } \\
\hline Males & 50 & 50 & 100 \\
\hline Females & 50 & 50 & 100 \\
\hline Total & 100 & 100 & 200 \\
\hline \multicolumn{4}{|l|}{ Age range } \\
\hline$<20$ years & 14 & 13 & 27 \\
\hline $21-25$ & 26 & 18 & 44 \\
\hline $26-30$ & 27 & 39 & 66 \\
\hline $31-35$ & 16 & 17 & 33 \\
\hline $36+$ & 17 & 13 & 30 \\
\hline Total & 100 & 100 & 200 \\
\hline \multicolumn{4}{|c|}{ Mean NORs counts } \\
\hline$>2.00$ & 16 & 0 & 16 \\
\hline$<2.00$ & 84 & 100 & 184 \\
\hline Total & 100 & 100 & 200 \\
\hline
\end{tabular}

TABLE 1: Distribution of the cases and controls by age, sex, and mean NORs counts.

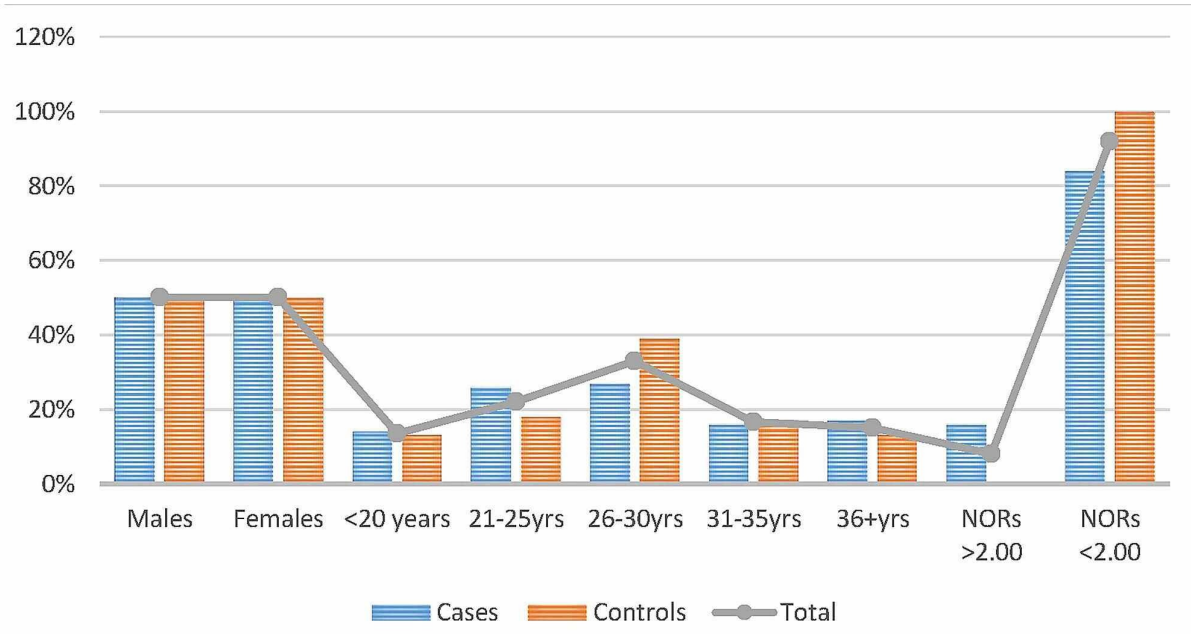

FIGURE 1: Description of the cases and controls by age, sex and mean NORs counts.

NORs, nucleolar organizer regions 


\section{Cureus}

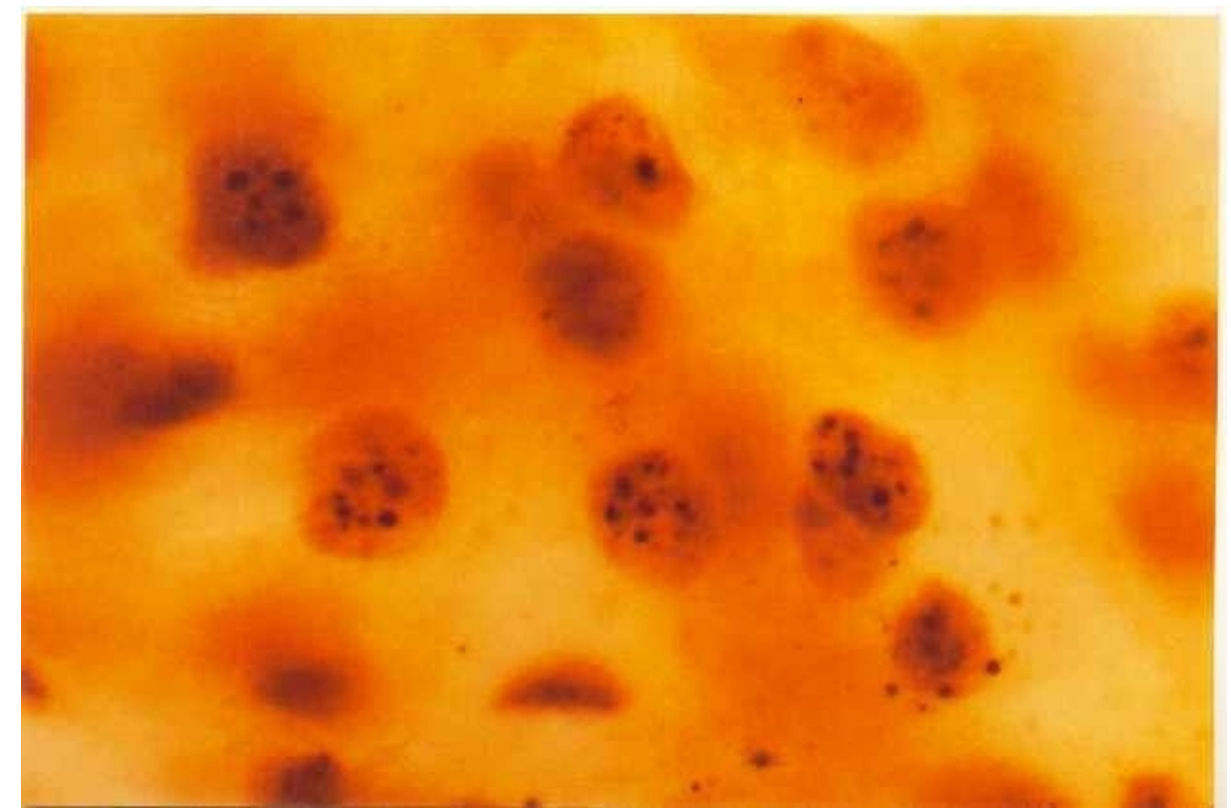

FIGURE 2: AgNOR stained sputum obtained from individuals exposed to smoking (case). The smears showing mean NORs counts of $>\mathbf{2 . 0 0}$ (black dots within the nuclei of the cells).

AgNOR, argyrophilic NORs; NORs, nucleolar organizer regions

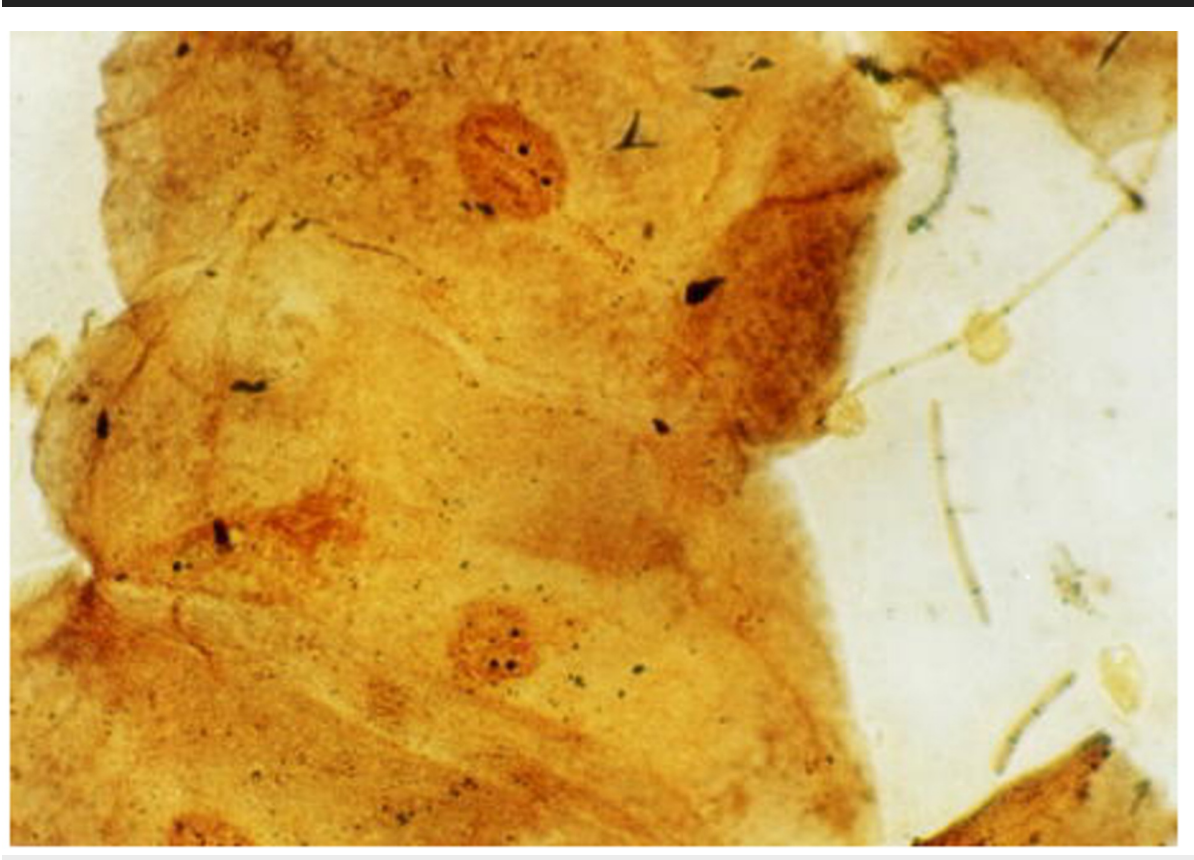

FIGURE 3: AgNOR stained sputum obtained from individual nonexposed to smoking (control). The smears showing mean NORs counts of $<2.00$ (black dots within the cells' nuclei).

AgNOR, argyrophilic NOR; NORs, nucleolar organizer regions 


\section{Cureus}

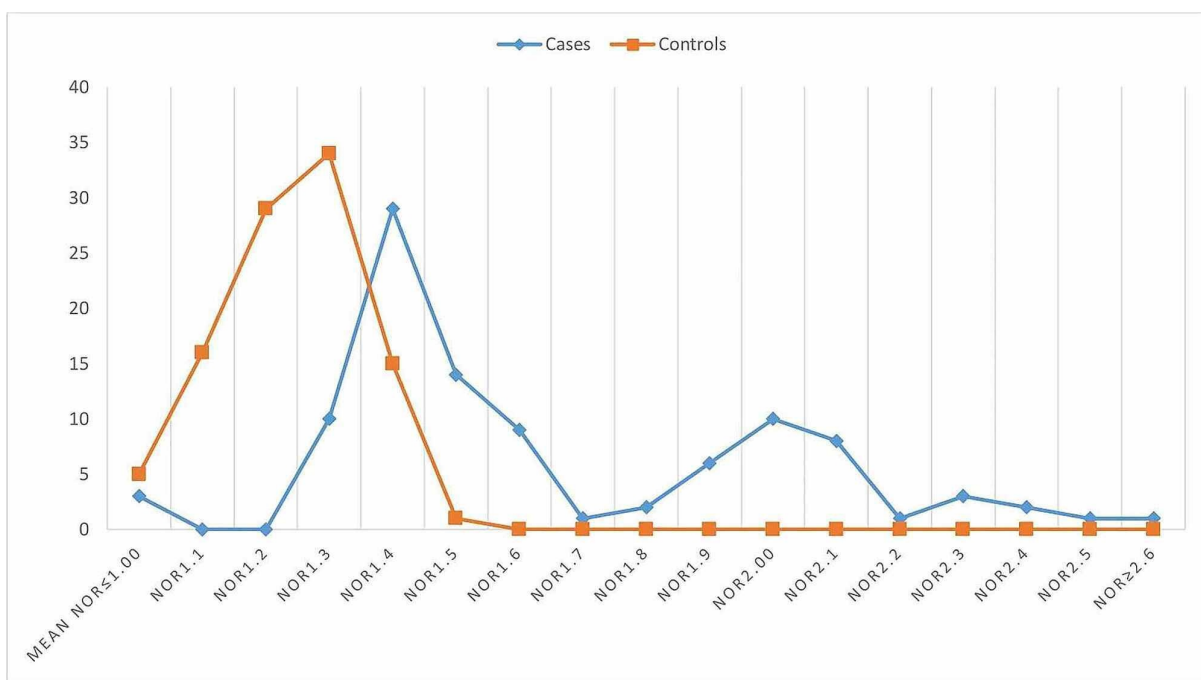

FIGURE 4: Description of the study subjects by mean NORs counts.

NORs, nucleolar organizer regions

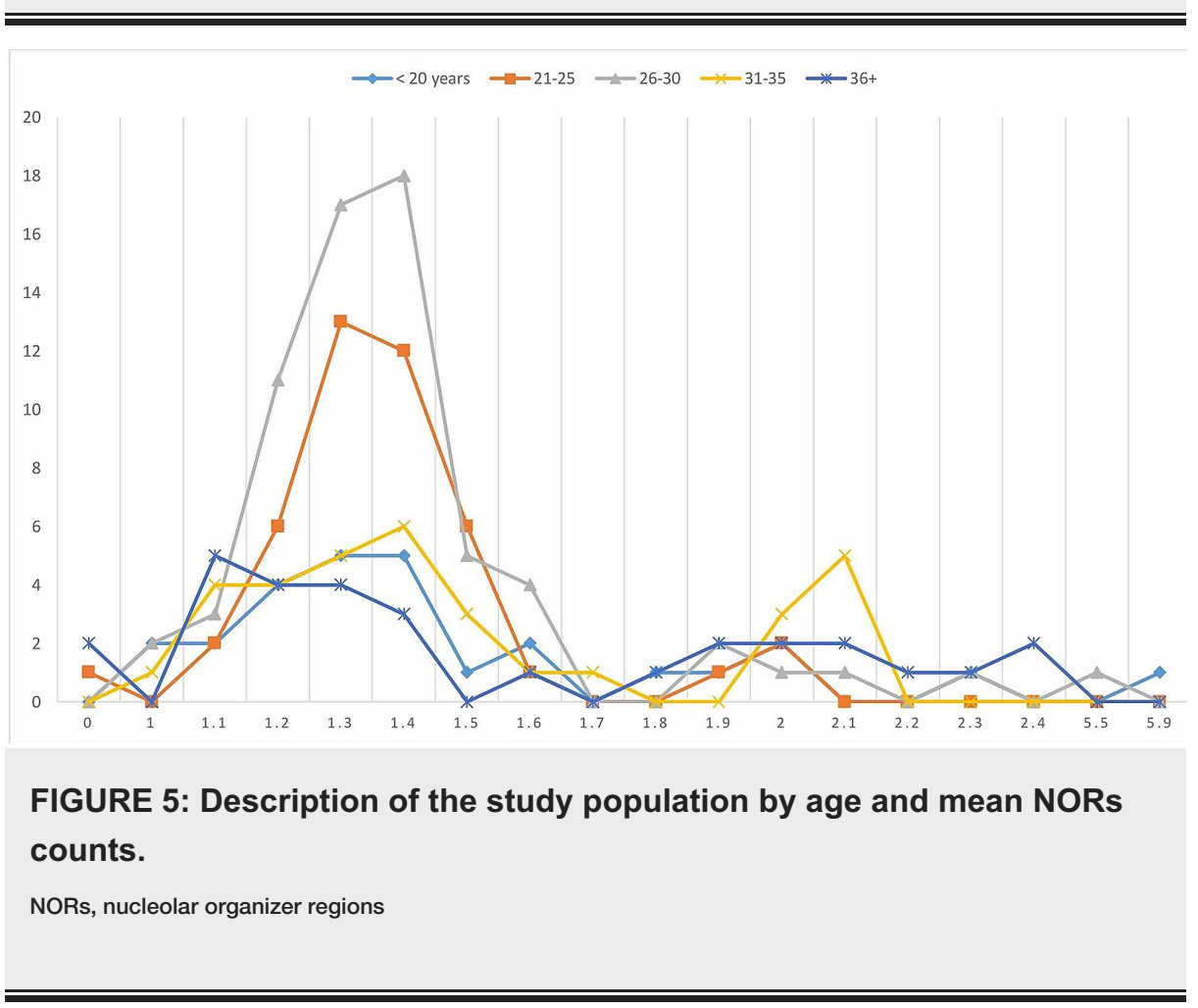




\section{Cureus}

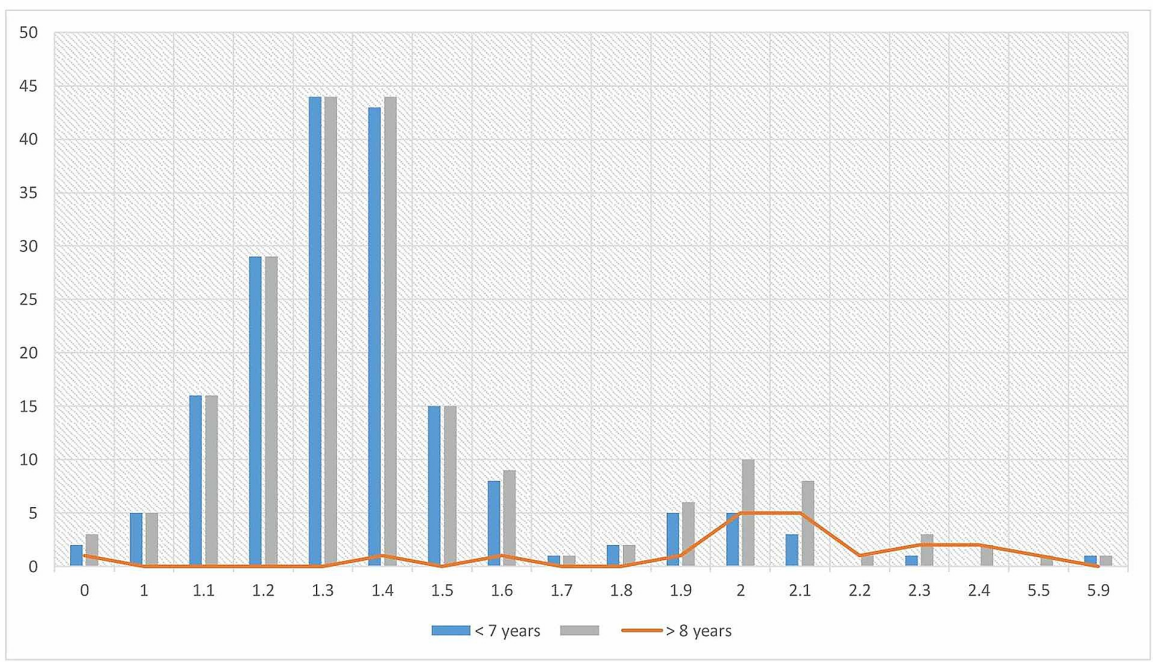

FIGURE 6: Description of the study subjects by mean of NORs counts and duration of exposure to smoking exposure.

NORs, nucleolar organizer regions

\section{Discussion}

The finding of a simple, specific, and cost-effective method for early detection of cancerous and precancerous conditions represents an emergent need for continuous screening of at-risk populations. Sputum cytology is a suitable method for screening of people at risk of developing lung cancer, but it has some limitations as it depends on qualitative measures. AgNOR as a quantitative method can be a suitable counterpart filling limitation in traditional cytology. Therefore, the current study aimed to assess the utility of NORs quantitation in early prediction of lung neoplastic transformation.

It is well documented that lung exposure to tobacco smoking has diverse pathological effects including lung neoplastic transformation [16].

In the present study, all cytological smears showing lung squamous metaplasia were found with mean NORs count $>2.00$, which indicates the merit of AgNORs count in the prediction of lung neoplastic transformation and therefore, suitable as a screening tool for an at-risk population. Higher NORs count usually an indication for cellular proliferation, which is considered as an initial step towards neoplastic progression [17]. These nuclear regions are associated with rDNA which usually indicates cellular activity, mostly related to cell division [18].

AgNORs count method was widely used in oral exfoliative cytology particularly among cigarette smokers to predict early cellular proliferative activity indicating neoplastic change [19], but its use for lung cytology is scarce [20]. It was reported that cellular proliferative quantified by AgNORs might play a substantial role in the early detection and diagnosis of premalignant and malignant lesions in the absence of clinical manifestations [21].

It was well established that the AgNORs quantification method is useful for early detection of cigarette smoking carcinogenic effects on the oral epithelial cells [22]. However, the utility of AgNORs count was not being applied in lung cancer in recent years, though some ancient reports have documented the relationship. The NORs have been utilized in nonsmall cell lung cancer associated with clinical and pathological parameters [23].

On the other hand, the role of cigarette smoking in the etiology of lung neoplastic transformation is well documented [24-25]. Cigarette smoking is prevalent in Saudi Arabia, especially amongst the younger generation [26], which necessitates urgent tobacco prevention control measures at community levels. 


\section{Conclusions}

Nucleolar organizer regions count is a simple, cost-effective, and reliable method that can give a quantitative measurement for the risk of lung neoplastic transformation. For at risk-population (tobacco users), it is recommended to perform the AgNORs method beside sputum cytology.

\section{Additional Information}

\section{Disclosures}

Human subjects: Consent was obtained by all participants in this study. Human Research Ethics Committee, College of Medicine, University of Ha'il issued approval HREC 00121/CM-UOH.04/20. Ethics approval letter Date: 05 April 2020 Ref No.: EC-00121 Dear: Hussain Ahmed The Human Research Ethics Committee (HREC) has reviewed and discussed your application to conduct the project outlined below. Approval No. HREC 00121/CM-UOH.04/20 Project Title Effects of cigarette smoke and Shabba Smoke on the lung epithelial tissues: A cytological case control study in Hail Principle investigator Hussain Ahmed Approval date 05April 2020 Expiry date 05Feb 2021 HREC Decision Approved The Researchers should comply with the following approval conditions: 1-Conduct the project rigorously in covenant with the protocol submitted, and decided the ethics approval, together with any changes made to the proposal prerequisite by the HREC. 2-Consult (email: postgraduatescientific@gmail.com) instantly of any complaints or other issues linked to the protocol, which may justify the review of the ethical approved of the proposal. 3-Make submission for approval of modifications to the approved proposal before employing such changes. 4-Send a headway report for every year of the approval. 5-Send final report when the project is complete. 6 Notify in writing if the project has been discontinued. Note: Failure to comply with above stated conditions may result in withdrawal of the approval for the proposal. . Animal subjects: All authors have confirmed that this study did not involve animal subjects or tissue. Conflicts of interest: In compliance with the ICMJE uniform disclosure form, all authors declare the following: Payment/services info: All authors have declared that no financial support was received from any organization for the submitted work. Financial relationships: All authors have declared that they have no financial relationships at present or within the previous three years with any organizations that might have an interest in the submitted work. Other relationships: All authors have declared that there are no other relationships or activities that could appear to have influenced the submitted work.

\section{Acknowledgements}

The authors would like to thank participants and people at the Department of Pathology, College of Medicine, University of Ha'il for their assistant in sample processing.

\section{References}

1. Canada THE: Canadian Tobacco Use Monitoring Survey. 2015. https://doi.org/10.1016/j.drugalcdep.2015.07.680

2. WHO. Tobacco. Fact Sheet. (2018). https://www.who.int/news-room/fact-sheets/detail/tobacco.

3. American Cancer Society: Non-small Cell Lung Cancer Survival Rates, by Stage . American Cancer Society, Inc., Atlanta; 2016.

4. Conway EM, Pikor LA, Kung SH, et al.: Macrophages, inflammation, and lung cancer. Am J Respir Crit Care Med. 2016, 193:116-130.

5. Team NLSTR: Reduced lung-cancer mortality with low-dose computed tomographic screening. N Engl J Med. 2011, 365:395-409. 10.1056/NEJMoa1102873

6. Tanner NT, Kanodra NM, Gebregziabher M, et al.: The association between smoking abstinence and mortality in the National Lung Screening Trial. Am J Respir Crit Care Med. 2016, 193:534-541.

7. Hahn EJ, Rayens MK, Hopenhayn C, Christian WJ: Perceived risk and interest in screening for lung cancer among current and former smokers. Res Nurs Health. 2006, 29:359-370.

8. Moyer VA: Screening for lung cancer: US Preventive Services Task Force recommendation statement . Ann Intern Med. 2014, 160:330-338.

9. Crocker J, Boldy DA, Egan MJ: How should we count AgNORs? Proposals for a standardized approach . J Pathol. 1989, 158:185-188.

10. McStay B: Nucleolar organizer regions: genomic 'dark matter’requiring illumination. Genes Dev. 2016, 30:1598-1610. 10.1101/gad.283838.116

11. Sharma R, Kumar G: Significance of silver binding nucleolar organizer regions in oral squamous cell carcinomas. Int J Sci Study. 2016, 3:193-197. 10.17354/ijss/2016/147

12. Cabrini R, Schwint A, Mendez A, Femopase F, Lanfranchi H, Itoiz M: Morphometric study of nucleolar organizer regions in human oral normal mucosa, papilloma and squamous cell carcinoma. J Oral Pathol Med. 1992, 21:275-279.

13. Urbanowicz I, Stacherzak J, Pawlik MW: AgNOR w rozrostach układu chłonnego . Clin Exp Med. 2005, $14: 1225-1235$.

14. Kaneko S, Ishida T, Sugio K, Yokoyama H, Sugimachi K: Nucleolar organizer regions as a prognostic indicator for stage I non-small cell lung cancer. Cancer Res. 1991, 51:4008-4011.

15. Ahmed HG, Babiker AE: Assessment of cytological atypia, AgNOR and nuclear area in epithelial cells of normal oral mucosa exposed to toombak and smoking. Rare Tumors. 2009, 1:18. 10.4081/rt.2009.e18

16. Zhou G: Tobacco, air pollution, environmental carcinogenesis, and thoughts on conquering strategies of lung cancer. Cancer Biol Med. 2019, 16:700-713. 10.20892/j.issn.2095-3941.2019.0180 


\section{Cureus}

17. Caragine CM, Haley SC, Zidovska A: Nucleolar dynamics and interactions with nucleoplasm in living cells . Elife. 2019, 8:e47533. 10.7554/eLife.47533

18. Gall JG: The human nucleolus organizer regions. Genes Dev. 2019, 33:1617-1618. 10.1101/gad.334748.119

19. van Sluis M, van Vuuren C, Mangan H, McStay B: NORs on human acrocentric chromosome p-arms are active by default and can associate with nucleoli independently of rDNA. Proc Natl Acad Sci USA. 2020, 117:10368-10377. 10.1073/pnas.2001812117

20. Vyas T, Verma P, Abidullah M, et al.: Quantitative analysis of AgNOR counts and pap stain in exfoliative cytology specimens of oral mucosa in bidi smokers and nonsmokers. Ann Afr Med. 2018, 17:210-214. 10.4103/aam.aam_69_17

21. Saba R, Halytskyy O, Saleem N, Oliff IA: Buccal epithelium, cigarette smoking, and lung cancer: review of the literature. Oncology. 2017, 93:347-353. 10.1159/000479796

22. Martins S, Zoehler B, Busin CS, et al.: Evaluation of cellular proliferative activity in patients with actinic cheilitis through silver-stained nucleolar organizer region method. J Contemp Dent Pract. 2018, 19:384-388.

23. Dogenski LC, de Figueiredo Ribeiro S, Gambin DJ, et al.: Oral leukoplakia-epidemiological survey and histochemical analysis of 107 cases in Brazil. Clin Oral Investig. 2020, 10.1007/s00784-020-03488-x. 10.1007/s00784-020-03488-x

24. Kobyakov DS, Avdalyan AM, Lazarev AF, Lushnikova EL, Nepomnyashchikh LM: Argyrophilic nucleolar organizer region in MIB-1 positive cells in non-small cell lung cancer: clinicopathological significance and survival. Cancer Biol Med. 2014, 11:264-269. 10.7497/j.issn.2095-3941.2014.04.005

25. Bade BC, Dela Cruz CS: Lung cancer 2020: epidemiology, etiology, and prevention . Clin Chest Med. 2020, 41:1-24. 10.1016/i.ccm.2019.10.001

26. Alqahtani WS, Almufareh NA, Al-Johani HA, et al.: Oral and oropharyngeal cancers and possible risk factors across Gulf Cooperation Council countries: a systematic review. World J Oncol. 2020, 11:173-181.

$10.14740 /$ wjon 1283 